\section{Prevalence of neurological complications associated with Zika virus in a brazilian metropolis}

\author{
Kattiucy Gabrielle da Silva Brito, 1 \\ Edarlan Barbosa dos Santos, 1 \\ Liliane dos Santos Maia Lucas, ${ }^{1}$ \\ Marco Orsini, 2,3 Rossano Fiorelli, ${ }^{2}$ \\ Silmar Teixeira, ${ }^{4}$ Carla Ayres, ${ }^{4}$ \\ Luan Correia, ${ }^{4}$ Victor Hugo Bastos, ${ }^{4}$ \\ Eduardo Trajano, 2 \\ Carlos Eduardo Cardoso, ${ }^{2}$ \\ Marcos R.G. de Freitas, 5 \\ Antônio Marcos da Silva Catharino1,6 \\ 1 University Iguaçu (UNIG), School of \\ Medicine, Nova Iguaçu, Rio de Janeiro; \\ 2 Masters Program Applied Science to \\ Health, Severino Sombra University \\ Vassouras; Science Rehabilitation \\ Program, UNISUAM, Rio de Janeiro; \\ ${ }^{3}$ Laboratory Mapping and Cerebral \\ Plasticity (LAMPLACE/UFPI), Federal \\ University of Piauí; ${ }^{4}$ Laboratory of \\ Brain Mapping and Functionality \\ (LAMCEF/UFPI), Federal University of \\ Piauí; 5Rio de Janeiro Federal \\ University (UFRJ), Neurology Service, \\ Rio de Janeiro; ${ }^{6}$ Geral Hospital of Nova \\ Iguaçu, Nova Iguaçu, Rio de Janeiro, \\ Brazil
}

\begin{abstract}
The aim of this paper is to study the prevalence of Zika Virus (ZIKV) and the index of its neurological complications. This is a quantitative, cross-sectional epidemiological study. Data were collected through the compulsory notification of suspected ZIKV and its neurological alterations cases. 113 suspected ZIKV cases were reported, most of them in the summer, with a higher prevalence of females and in the fourth decade of life. Among the neurological changes, 15 Guillain-Barré Syndrome cases were reported, with one registered death. As neurological manifestations, most of them started 30 days after a ZIKV infection. No case has been confirmed laboratory. It is necessary to combat the vector, mainly in the summer, to reduce ZIKV infection and its neurological complications, besides instruction to the health professionals about these complications and serological tests requests for an accurate diagnosis.
\end{abstract}

\section{Introduction}

The Zika virus fever is a disease caused by a virus of the Flavivirus genus, Flaviviridae family, transmitted mainly by the Aedes aegypti and Aedes albopictus mosquitoes, being also documented the transmission by sexual relation and blood transfusion.1,2 Virus circulation in Brazil was laboratory confirmed in April 2015.3

Because it is a poorly described disease, its clinical characterization and natural history are based on a limited number of case reports and outbreak investigations. It is estimated that only $18 \%$ of human infections result in clinical manifestations, being, therefore, more frequent the asymptomatic infection. 4,5 Considering that it is an emerging disease in Brazil with death, increased cases of microcephaly and neurological manifestations, these being possibly associated with the disease, the Health Surveillance Department (HSD) recommends to the State and Municipal Offices, the compulsory notification of all suspected cases, established in Ordinance No. 204 of February 17, 2016.3

The ZIKV infection clinical symptoms are nonspecific and therefore, it may be confused with other febrile diseases, especially Dengue fever and Chikungunya fever. In view of the similarity of symptoms related to febrile illness, patients do not seek health services, which contribute to the underreporting of cases. ${ }^{6}$

The symptoms are similar to Dengue symptoms, such as low fever $\left(37.8^{\circ} \mathrm{C}\right.$ and $38.5^{\circ} \mathrm{C}$ ), arthralgia (on wrists and ankles, with or without edema), myalgia, headache with retro-ocular pain rashes accompanied by itching. It may also cause abdominal pain, diarrhea, constipation, photophobia, conjunctivitis and small ulcers in the oral mucosa. ${ }^{7}$

ZIKV protective measures recommended by the Brazilian Ministry of Health include keeping doors and windows closed or screened, wearing pants and a longsleeved shirt, as well as the use of repellents. However, the main strategy for the reduction of the vector population requires a collective, universal and intersectoral effort. ${ }^{8}$

Guillain-Barre syndrome (GBS) is the largest cause of generalized flaccid paralysis in the world, 9,10 with annual incidence of 1-4 cases per 100,000 inhabitants and peak between 20 and 40 years of age. No specific epidemiological data for Brazil, only the disease subtypes distribution. ${ }^{11}$ GBS is an autoimmune disease that primarily affects the myelin of the proximal portion of the peripheral acute or subacute nerves. ${ }^{12,13}$
Correspondence: Kattiucy Gabrielle da Silva Brito, Rua Ministro Lafaiete de Andrade, 1560, bl 02 ap 402, Cep: 26261-220, Nova Iguaçu RJ, Brazil.

E-mail: kattiucy_brito@hotmail.com

Key words: Zika virus; Guillain-Barré syndrome; microcephaly; infection.

Contributions: the authors contributed equally.

Conflict of interest: the authors declare no conflict of interest.

Funding: none.

Received for publication: 12 February 2018. Revision received: 13 February 2018.

Accepted for publication: 19 February 2018.

This work is licensed under a Creative Commons Attribution NonCommercial 4.0 License (CC BY-NC 4.0).

(C) Copyright K.G. da Silva Brito et al., 2018 Licensee PAGEPress, Italy

Neurology International 2018; 10:7638

doi:10.4081/ni.2018.7638

According to the GBS's clinical protocol and therapeutic guidelines, the risk factors identified, the disease initial stage and the fast and adequate referral for the specialized care, give to the Basic Attention an essential character for a better therapeutic result and prognosis of the cases. ${ }^{14,15}$

However, it is necessary to observe the lower limbs weakness cases, reported by patients with suggestive ZIKV conditions. The GBS diagnosis is based on the lower limbs weakness clinical manifestations and also on the classic protein-cytokine dissociation in the cerebrospinal fluid. Usually, this finding is not found on the first lumbar puncture, therefore making it necessary to repeat the procedure to show the change. In some GBS cases caused by ZIKV, the appearance of clinical manifestations is early, approximately two weeks after the clinically manifested infection. ${ }^{6}$

For the ZIKV fever treatment are indicated rest, hydration and symptomatic treatment. The administration of non-hormonal anti-inflammatories is contraindicated. In GBS cases, they should be treated immediately in a hospital environment, and intensive therapy's support is often necessary, in which immunoglobulin use is essential.?

The researchers verified that the GBS estimated rate among ZIKV patients needs to be confirmed and carefully screened in order to see if the apparent increase during the ZIKV epidemic reflects a real increase and not just an increase in reporting. They 
also point out that the most GBS patients in the current study reported ZIKV symptoms before the GBS onset and the majority of ZIKV cases are asymptomatic, the GBS risk may be grouped among symptomatic ZIKV infections patients. 14

In 2016, 214,193 ZIKV fever probable cases in the country were evaluated, and 128,266 of these cases $(59.9 \%)$ were confirmed. The incidence rate analysis of probable cases (/100 thousand inhabitants), according to geographic regions, shows that the Central-West region had the highest incidence rate: 219.2 cases/100 thousand inhabitants. In Rio de Janeiro state, 67,481 cases were reported with an incidence rate of 407.7 cases/100 thousand inhabitants. Six deaths by ZIKV were confirmed in the laboratory: 4 in Rio de Janeiro and 2 in Espírito Santo, between January and May. In relation to pregnant women, 16,923 probable cases were recorded, of which 10,820 were confirmed by clinical-epidemiological or laboratory criteria, according to Sinan-NET database. 16

This study had a goal to verified the prevalence of ZIKV reports and its complications index related to neurological alterations in the Nova Iguaçu Municipal Hospital in 2016.

\section{Materials and Methods}

A quantitative cross-sectional epidemiological study, carried out in the Nova Iguaçu city, in the metropolitan region of Rio de Janeiro state, located $28 \mathrm{~km}$ from the state capital. It has an estimated population of 807,492 inhabitants.

The data collection was performed at the Epidemiological Surveillance of the General Hospital of Nova Iguaçu (HGNI), obtaining the notification completion sheets of the National System of Aggravation and Notifications (SINAN), from January to December, 2016. The HGNI would be the local reference for severe neurological conditions, such as those studied here.

All the ZIKV reported cases and neurological complications associated with it in the HGNI in 2016 were included in the study, where all the data present in the notifications to assemble their epidemiological profile were analyzed. Neurological abnormalities include encephalitis, meningoencephalitis, myelitis, acute flaccid paralysis and Guillain-Barré syndrome. The time between viral infection by ZIKV and the beginning of the neurological condition was also evaluated through the notification.

The data were analyzed through the ZIKV reported cases quantification and verified the cases percentage with confirmed laboratory diagnosis. The areas where the patients lived were evaluated, having the greatest number of notifications.

The living areas were separated according to the administrative division of the city hall, which encompasses the 69 districts of the city and are then divided into the Government Regional Units in Centro; Posse; Comendador Soares; Cabuçu; Km32; Austin; Vila de Cava; Miguel Couto; Tinguá.

We excluded from the study, neurological alteration cases where other etiological agents were confirmed, for instance, Epstein-Barr, Herpes virus, Cytomegalovirus and Campylobacter or that presented another diagnosis by the physician, such as stroke, diabetic acidosis, among others.

The study was carried out after approval by the Research Ethics Committee of the HGNI, registration number 1,615,318, CAAE 56852416.0.0000.5254. We obtained a total of 113 reports of ZIKA and 15 reports of neurological complications associated with it. The collected data were stored and analyzed using the Microsoft Office Excel 2013 program. The data were consolidated in the form of graphs and tables with absolute numbers and percentage.

\section{Results}

\section{Zika virus}

During the study, were analyzed 113 ZIKV reports, with the highest number of cases in the summer period - from January to March, with a peak in March (32 cases), showing a significant decrease in notifications in the following months, as presented in Figure 1. All the notifications analyzed had as notifiers, agents of endemics or health.

The notifications predominance was of female patients, with $62.8 \%$ of the cases whereas in the male patients, the incidence was $37.2 \%$. The fourth decade of life was the most affected age group $(21.2 \%)$, followed by the third decade of life with $18.6 \%$ of the notifications. The color evaluation was impaired since it was not filled correctly or it was marked as ignored, as well as the patients' education.

The patients living area is a relevant fact due the ZIKV be a disease with vector transmission where we must combat the transmitting agents, enabling the realization of awareness and control campaigns of the Aedes Aegypit vector.

When analyzing notifications for housing, it was verified that the highest inci- dence of cases is in the region near the HGNI, in the Posse neighborhood with $41 \%$ of notifications, followed by others of patients from nearby places with $22 \%$ of report cases, verifying the result, we conclude that the hospital does not only serve the Nova Iguaçu city, but also serves the entire metropolitan region, as described in Table 1. The result found may not delimit the areas with the highest incidence of the disease in the city, since the data analyzed are limited to the HGNI, a hospital that attends urgency and emergency with medium and high complexity, which does not apply to ZIKV fever. For such delimitation, one should increase the notifications analyzed number. In the reports analyzed none of them contained confirmatory laboratory data, thus, all cases would be framed as suspect cases in the patients' clinic.

\section{Neurological complications associat- ed with Zika virus}

Fifteen cases were reported in the analyzed period, of which 8 were women and 7

Table 1. Distribution of housing in Nova Iguaçu areas or other places of Rio de Janeiro.

\begin{tabular}{lcc}
\hline Areas & N. & $\%$ \\
Centro & 23 & 20.4 \\
Posse & 46 & 41 \\
\hline Comendador soares & 4 & 3.5 \\
Cabuçu & 2 & 1.8 \\
\hline Austin & 5 & 4.3 \\
Miguel Couto & 5 & 4.3 \\
\hline Vila de Cava & 3 & 2.7 \\
Outros municípios & 25 & 22 \\
$\quad$ Belford Roxo & 5 & \\
Japeri & 1 & \\
$\quad$ Mesquita & 5 & \\
$\quad$ Nilopolis & 4 & \\
Queimados & 2 & \\
Rio de Janeiro & 3 & \\
São João de Meriti & 4 & \\
\hline
\end{tabular}

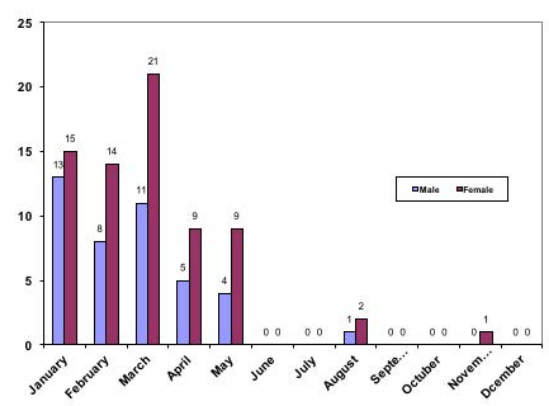

Figure 1. Distribution of Zika virus notifications in 2016 in the HGNI. 
were men. As shown in Table 2, the age group with the greatest involvement was in the fourth decade of life, with 1 death also recorded in this age group.

Notifications requesting confirmatory laboratory tests for ZIKV, as recommended by the Ministry of Health, except for the request for laboratory confirmation after death were found.

Neurological signs started after 15 days (13.4\%), 20 days $(20 \%)$ and 30 days (33.3\%) of the possible ZIKV infection, most of them with 30 days post infection. To point out, there were 5 notifications without this information (Table 2).

All reported cases were GBS, no other neurological abnormalities associated with ZIKV were reported in HGNI during 2016.

\section{Discussion and Conclusions}

The highest number of cases was reported in the summer period, showing a significant decrease in notifications in the following months, even months without notification, which corroborates the season-

Table 2. Epidemiological profile of neurological changes reported at HGNI in 2016.

\begin{tabular}{lcc} 
Variables & N & $\%$ \\
Period & & \\
March & 5 & 33.3 \\
April & 2 & 13.3 \\
May & 2 & 13.3 \\
June & 1 & 6.7 \\
July & 1 & 6.7 \\
August & 2 & 13.3 \\
October & 1 & 6.7 \\
November & 1 & 6.7 \\
Gender & & \\
Female & 8 & 53.3 \\
Male & 7 & 46.7 \\
\hline Age & & \\
10 to 20 years & 1 & 6.7 \\
20 to 30 years & 1 & 6.7 \\
30 to 40 years & 6 & 40 \\
40 to 50 years & 3 & 20 \\
60 to 70 years & 3 & 20 \\
70 to 80 years & 1 & 6.7 \\
Home & & \\
Centro & 5 & 33.3 \\
Posse & 3 & 20 \\
Comendador Soares & 1 & 6.7 \\
Austin & 3 & 20 \\
Município de Belford Roxo & 3 & 20 \\
\hline Time between onset of symptoms and ZIKV \\
15 days \\
20 days & 2 & 13.4 \\
30 days & 3 & 20 \\
No information & 5 & 33.3 \\
\hline & 5 & 33.3 \\
\hline
\end{tabular}

ality of the ZIKV infection. This draws attention to the urgent need for educational campaigns and fight against the vector, especially in the mentioned time of the year, so conducive to infection.

It was also observed a predominance of the female sex with $62.8 \%$ of the notifications, which would probably be related to the sexual transmission of the virus, which was not observed in the other arboviruses, but could also be related only to the tendency of the women to seek more medical attention that men. 17

In Brazil, a growing number of severe neurological complications among adults is related to the spread of ZIKV, according to some researches, an increase in admissions of patients with inflammatory complications such as GBS, myelitis and encephalopathy. ${ }^{18}$ Compared with a similar seasonal period prior to the first documented case of ZIKV, hospital admissions for GBS from 2015 to 2016 showed significant increases of 1.0 to 5.6 cases per month. 19

In this study, a relatively high number of hospitalizations for GBS were observed, where out of 15 cases reported, 10 said to have been preceded by ZIKV infection. Most of the neurological symptoms began 30 days after ZIKV infection. None of the reports presented a result or request of the serological test for ZIKV to confirm the previous infection, except for one case where the examination was requested after the death of the patient. In cases where ZIKV had not been previously mentioned, this hypothesis could not be ruled out if it were taken into consideration that the infection could occur asymptomatic. 20

The notifications by GBS associated to ZIKV, except for the month of March where more cases occurred, continued to be reported with a relatively average similar in the second semester.

Nowadays there is no preventive action known that may be taken to prevent neurological injury. We expect more studies in order to find out how this ZIKV neurotropism occurs and increase awareness of its neurological complications.

Therefore, more information and instruction is required from health professionals about these complications so that they follow the recommendations of the Ministry of Health and begin to request the serology for ZIKV in all suspect cases, in order to make an accurate diagnosis. Also, it is necessary a prevention against ZIKV since we do not have much information about it and these neurological complications.

\section{References}

1. Musso D, Roche C, Robin E, et al. Potential sexual transmission of Zika Virus. Emerg Infect Dis 2015;21:35961.

2. Musso D, Nhan T, Robin E, et al. Potential for Zika virus transmission through blood transfusion demonstrated during an outbreak in French Polynesia, November 2013 to February 2014. Euro Surveill 2014;19:pii20771.

3. Ministério da Saúde (BR). Departamento De Vigilância Das Doenças Transmissíveis. "Nota informativa SVS/MS que dá diretrizes para procedimentos a serem adotados para a vigilância da febre do vírus Zika no Brasil". Brasília: Ministério da Saúde. 2016.

4. Ministério da Saúde (BR). Secretaria de Vigilância em Saúde. Boletim Epidemiológico. Febre pelo vírus Zika: uma revisão narrativa sobre a doença. Brasília: Ministério da Saúde. 2015;46:1-7.

5. Nhan TX, Cao-Lormeau VM, Musso D. Les infections à virus Zika. Rev Francoph 2014;467:45-52.

6. Zanluca C, Melo VCA, Mosimann ALP, et al. First report of autochthonous transmission of Zika virus in Brazil. Mem Inst Oswaldo Cruz 2015;110:56972.

7. Caveião C. Vírus zika suas complicações relacionadas à microcefalia e guillain-barré. Cad. Esc Saúde 2016;1:3-6.

8. Ministério da Saúde (BR). Departamento de Vigilância das Doenças Transmissíveis. Protocolo de vigilância e resposta à ocorrência de microcefalia. Brasília: Ministério da Saúde. 2015.

9. Kieseier BC, Hartung HP. Therapeutic strategies in the Guillain-Barré syndrome. Semin Neurol 2003;23:159-68.

10. Vucic S, Kiernan MC, Cornblath DR. Guillain-Barré syndrome: an update. J Clin Neurosci 2009;16:733-41.

11. Dourado ME. Félix RH, da Silva WK, et al. Clinical characteristics of Guillain-Barré syndrome in a tropical country: a Brazilian experience. Acta Neurol Scand 2012;125:47-53.

12. Ministério da Saúde (BR). Portaria SAS/MS no 1171. "Protocolo Clínico e Diretrizes Terapêuticas Síndrome de Guillain-Barré. Brasília: Ministério da Saúde. 2015.

13. Ministério da Saúde (BR). Departamento De Vigilância Das Doenças Transmissíveis. Protocolo de vigilância dos casos de manifestações 
neurológicas com histórico de infecção viral prévia. Brasília: Ministério da Saúde. 2015.

14. Cao-Lormeau VM, Blake A, Mons S, et al. Guillain-Barré Syndrome outbreak associated with Zika virus infection in French Polynesia: a case-control study. Lancet 2016;387:1531-9.

15. Ministério da Saúde (BR). Boletim Epidemiológico. "Monitoramento dos casos de dengue, febre de chikungunya e febre pelo vírus Zika até a Semana Epidemiológica. Brasília: Ministério da Saúde. 2017;48:1-10.
16. Foy BD, Kobylinski KC, Chilson Foy $\mathrm{JL}$, et al. Probable non-vector-borne transmission of Zika virus. Emerg Infect Dis 2011;17:880-2.

17. Coelho FC. Durovni B, Saraceni V, et al. Higher incidence of Zika in adult women than adult men in Rio de Janeiro suggests a significant contribution of sexual transmission from men to women. Int J Infect Dis. 2016;51:12832.

18. Silva IRF, Frontera JA, Bispo de Filippis AM, et al. for the RIO-GBSZIKV research group, neurologic com- plications associated with the zika virus in brazilian adults. JAMA Neurol 2017;74:1190-8.

19. Araujo LM, Ferreira MLB, Nascimento OJM. Guillain-Barré syndrome associated with the Zika virus outbreak in Brazil. Arq Neuropsiquiatr 2016;74:253-5.

20. Wiwanitkit S, Wiwaitkit V. Afebrile, asymptomatic and non-thrombocytopenic Zika virus infection: Don't miss it!. Asian Pac J Trop Med 2016;9:513. 